\title{
Timeline-Based Multi-Need Analysis and Design: Pretest for Measurement Usefulness and Ease of Use
}

\author{
Hi-Yeob Joo ${ }^{1}$, Jong-Oh Park ${ }^{2}$ and Sea Woo Kim ${ }^{3}$ \\ ${ }^{1}$ Korea Electronics Technology Institute, Republic of Korea \\ ${ }^{2}$ Business Administration Dept., Soongeui Women's College, Republic of Korea \\ ${ }^{3}$ Digital Media Dept., Soongeui Women's College, Republic of Korea \\ ${ }^{1}$ hyjoo74@gmail.com, ${ }^{2}$ dauphine@sewc.ac.kr, ${ }^{3}$ coolgate@sewc.ac.kr
}

\begin{abstract}
New business model is a key of company for a sustainable growth. Many companies try to develop new service and product in order to develop and keep existing customers. NSD (New Service Development), NPD (New Product Development) represented by the new business opportunities derived from the analysis of the customer for understanding what they want. The environmental change, such as development of ICT (Information and Communication Technology) and the emergence of the various media let peoples' needs to be more diverse and rapidly changeable. This paper shows the process of extracting needs using an empirical study. For this, we divided the 90 respondents into three groups (each group 30 people) by time interval 10, 30 and 60 minutes. Result shows that shorter interval time makes more need selections and less response rate.
\end{abstract}

Keywords: Need Design, Multi-need Analysis, Time Interval Analysis, Needs Priorityselection

\section{Introduction}

Unforeseen products and services such as Smartphone, SNS (social network service), and social commerce services have become popular in the market. Application for smart phone, AppStore, touch screen, social commerce and feedback using social network, bulk buy and peer network service, the common points are the 'Design of hidden desire of customer, and make people to recognize hidden needs'. These create the new market and build a strong entrance barrier for market dominance. This new trend leads the companies which have been focused on the manufacturer based marketing analysis and strategy to create an innovative plan for the new industry. It means that new future business is not a market entry but a market formation. ${ }^{1}$

To make it short, analysis for customer needs (multi and hidden) become the main issue. Customer analysis is a basic and necessary for the new business development. Previous research started from understanding customer and need-analysis. However, this method is focused on pre-defined the product and market. Therefore, it has limitation on creating a new market and product and become an industry leader. The causes for the new trend are IT technology development and various media create the rich customer knowledge and experience. In other words, customer needs are more specified and individualized. Super consumer, prosumer and cresumer are the symbols of the change trend in customers' need complexity.

Therefore, business director should fine the customers' potential need and lead then to purchase the product or service that the company suggested. Finding the hidden need and predict the purchase intention time (purchase intention) should be required. But there are two limitations. One is that we don't know the reliable measurement and optimal time interval. The other is that we have to ensure the validity of newly design model. 
Therefore, major research topics are (1) How customer analysis method for deriving a new business would be designed?, (2) What are the different factors between existing and newly designed model?, (3) How could we get a validity/reliability of newly designed model?, and (4) What should be added in the newly designed model further?

This paper suggests the timeline-based approach for customer need analysis. TPOM (time, place, occasion, and money) are four affecting factors in our model. Our final goal is analyze the hidden needs on the timeline to define the new need and predict the change patterns. For this, we use an empirical study to show the optimal time-interval and components of newly designed model.

\section{Theoretical Background}

\subsection{Concept of the Needs}

Human need is the basic element for product and service merchandising. Despite there have been many tries to define the 'need', but still has not presented clearly yet. Kotler and Armstrong (1991) define perceived deficiency as perception stage and categorized into three phases, biological, social, and individual. Arndt (1978) defined needs, separates from wants, demand, and is a basic and necessary for metal stability. Shiffman \& Kanuk (1987) discriminates biological desire from environmental and cultural desire.

They concluded that need could not be met fully because people had some different needs in the same times. Also, after achieved one need, it is possible to rise a different need. We believe that to analyze the need, it is necessary to consider the multi needs existence in the same time.

Additionally, as education level increase, IT (information technology) development and SNS (social network service) spreads, expressing individual desire could be suppressed. Expressing pure desire could be hindered by social status and responsibility. Noblesse oblige and social responsibility are some examples.

Finding a new value of potential customers, we are able to detect the suppressed need. It will cause a new designed product or service can attract customer's willing to pay. It means that future business should be focused on not a market selection but a market formation as shown Figure 1. ${ }^{1}$

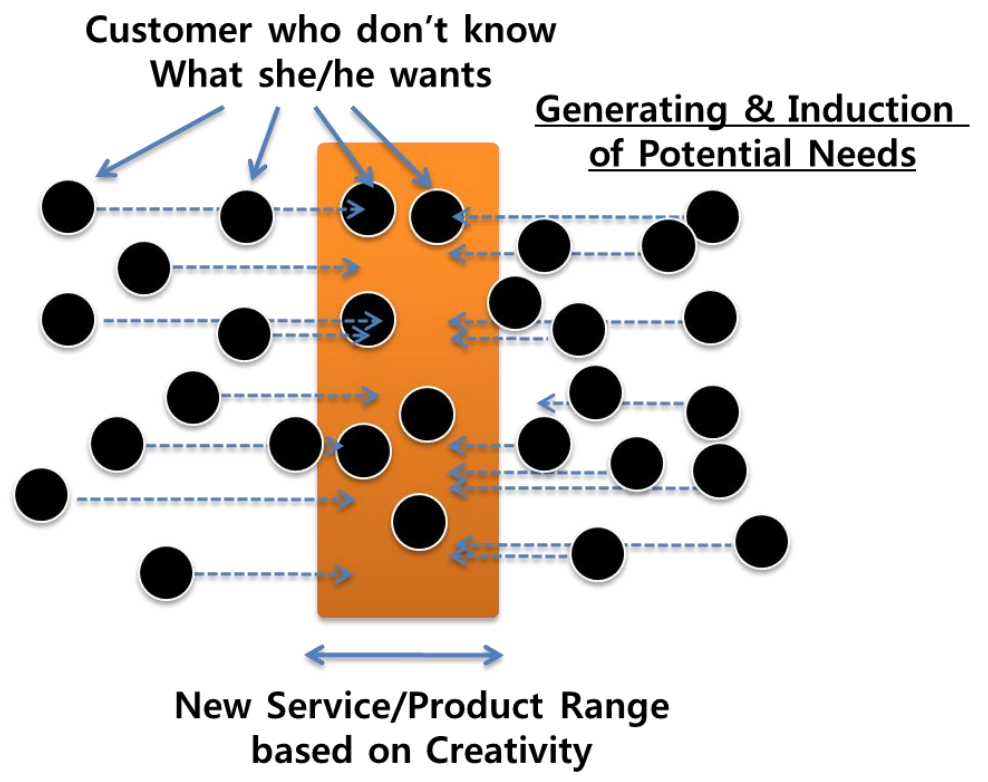

Figure 1. Future Business Approach 
In these days people cannot recognize what they want exactly. As various media stimulate customers consistently and make them confused. This leads the more time for decision making. Joo and Kim (2012) raised the importance of timeline based analysis of need. Also, emphasized the importance of infusion of need by analyzing the multi need degreed measurement.

\subsection{Existing Customer Analysis Methodology}

Calculation need based on psychology and research on quantitative analysis gains importance by open-closed questionnaire for outcome based segmentation ${ }^{6}$, job mapping ${ }^{7}$ and empathic design. ${ }^{8}$ There are other methods such as brain storming, behavior analysis, value analysis, Delphi, and scenario methods are also used. ${ }^{9}$

Previous researches have been focused on customers' expected level with a certain time and formalized them into some categorized sectors to penetrate into pointed target markets as shown in Figure 2.

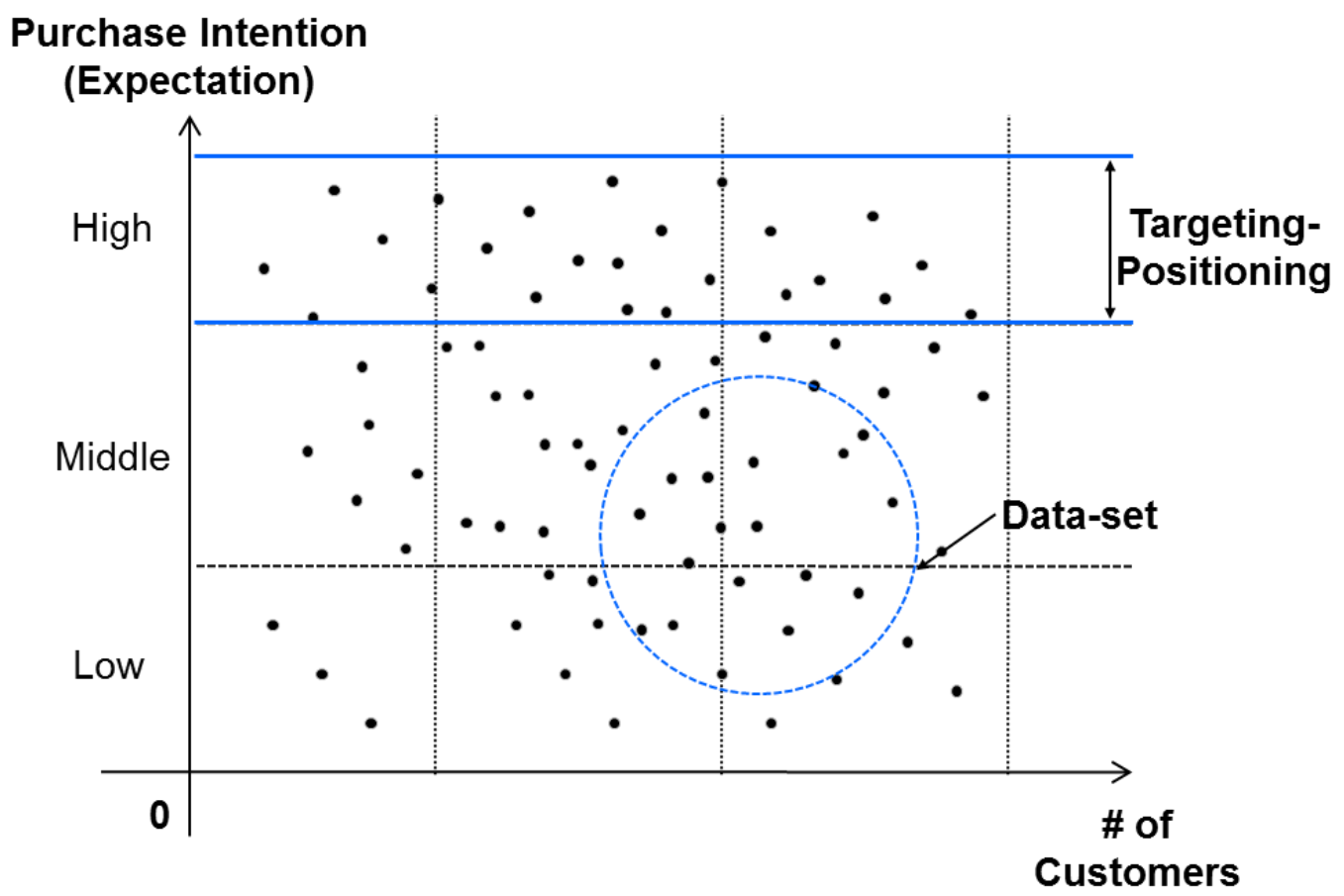

Figure 2. Previous Customer's Needs Measurement Logic

Data-set that measured in a certain time, it could be classified by age, sex, province, education level, income and etc.. It has been focused on positioning which has been based on certain market penetration. Such methodologies are expected to a certain point and the evaluation results of the judgment by applying a statistical hypothesis error can occur. It means that alpha and beta statistical errors. In other words, one is that he/she is a real customer, but is not supposed as a real customer. The other is he/she is not a real customer, but is supposed as a real customer. This leads to the ambiguous customer specification. Finally, leads to the wrong strategy for attracting new customers and sustain the current customers. Big data analysis and improved computing power can leads to the persistent customer need change analysis. 


\section{Timeline Based Multi-Need Analysis}

This research suggests TPOM based analysis model. In this model, the following three were designed based on the hypotheses. First, the customer's needs in accordance with the passage of time will have a specific pattern. Secondly, the stimulus patterns are TPOM by level will change. Finally, various needs exist in the same time zone, a difference in level between the product properties will vary according to preference. The method to analyze the differences between the needs of the widely used statistical concept of confidence interval was used.

Figure 3. shows that consumers can have the same time period needs are varied; the change is determined by TPOM, which includes a representation of the possible existence of a certain pattern. It can show the customer's service/product purchase intention probability by confidence interval. Also marketing director gets an opportunity of promotion and finding out the new customer precisely under the low reliability.

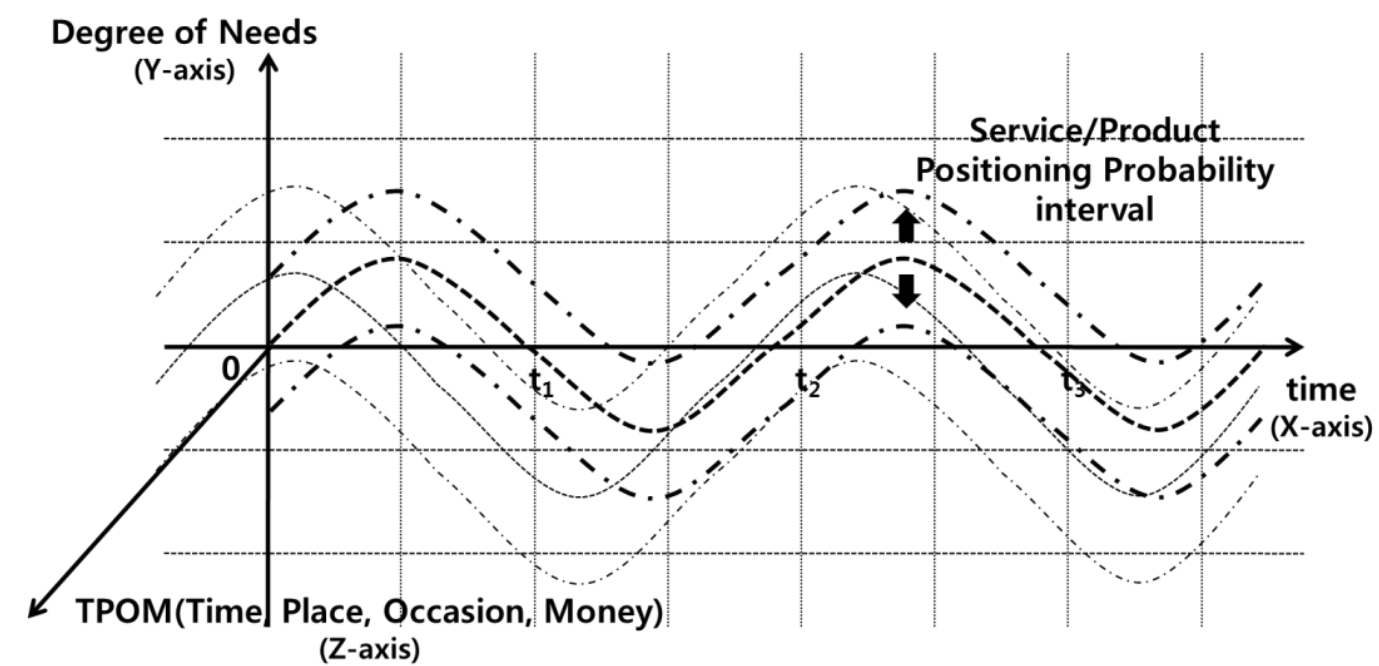

Figure 3. Concept of Timeline Based Multi-need Analysis

\section{Research Experiment Design \& Results}

\subsection{Research Experiment Design}

To verify the credibility we suggest research method as shown in Figure 4 . We would like to gather the data-set and extract some patterns of need change. A question 'What is your usual smartphone app do you use most often?' is provided via smartphone app. We added some situation variables such as TPOM, to evaluate the properties of the respondents. 'What is your most valuable item among time, place, occasion and money (purchase power)?' was asked. Response were collected and analyzed by TPOM based.

There are some advantages in this method. First, wide perspectives of new business opportunities are possible. Second, we can draw the framework for new markets with various points of view. Finally we can set the new direction of new business formation. 


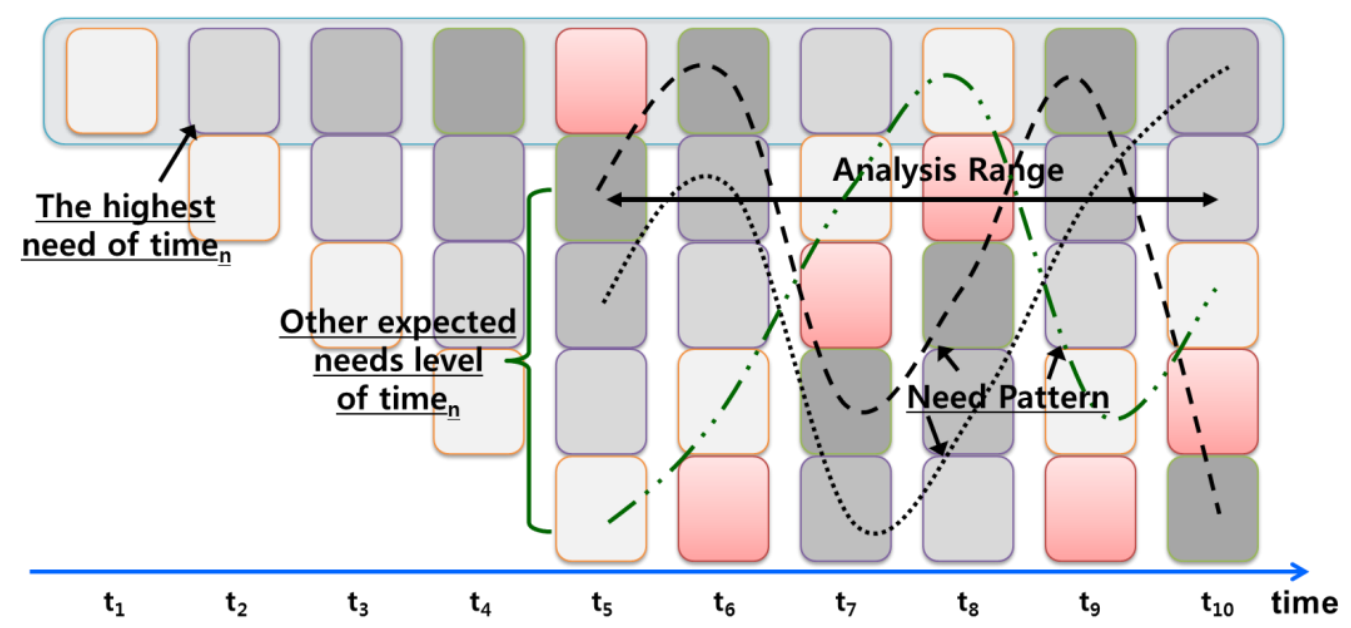

Figure 4. Research Design

\subsection{Data Collection}

We had a pre-test to derive a proper time-interval during 2014 February 9 to February 11 for 10/30/60 min intervals ( 3 types) by 30 people. Table 1 shows the demographic information. The purpose of this study is to derive a variety of needs, and women ages 10 to 20 are very familiar with a Smartphone, they were selected as the main target.

Table 1. Demographic Information

\begin{tabular}{c|c}
\hline Sample $(\mathrm{n})$ & 90(each group, 30) \\
\hline Age & $19 \sim 21$ \\
\hline Sex & Female \\
\hline Region & Seoul \& Gyeonggi-do \\
\hline
\end{tabular}

\subsection{Results}

To determine the ease of use and usefulness of the measurement method, we analyze the response rate and valid value. As a result, 30-min group's response and valid value was highest as shown in Table 2. And 60-min group's percentage of valid value was highest, too. It means that ease of use and usefulness of 30-minutes group is most advantageous.

Table 2. Ease of Use and Usefulness

\begin{tabular}{c|c|c|c|c|c}
\hline \multirow{2}{*}{} & \multirow{2}{*}{$\begin{array}{c}\text { \# of } \\
\text { samples }\end{array}$} & \multicolumn{2}{|c|}{ response* $^{*}$} & \multicolumn{2}{c}{ \# of valid value } \\
\cline { 3 - 6 } & & number & $\%$ & number & $\%$ \\
\hline $10-\min$ & 30 & 17 & $56.7 \%$ & 6 & $20.0 \%$ \\
\hline $30-\min$ & 30 & 23 & $76.7 \%$ & 12 & $40.0 \%$ \\
\hline $60-\min$ & 30 & 19 & $63.3 \%$ & 12 & $40.0 \%$ \\
\hline
\end{tabular}

* who are response at least 1 time

** over $40 \%$ response of total trial 
In addition, to determine the effectiveness and efficiency of the measurement method, we analyze the questionnaire response and extracting number of needs. As a result, 60min group's average number of response was highest and 30-min group followed as shown in Table 3. It means that effectiveness of 60-minutes group is most advantageous. But its elapsed time was too long to gather data-set.

Table 3. Effectiveness

\begin{tabular}{c|c|c|c|c}
\hline \multirow{2}{*}{} & \multicolumn{2}{|c|}{ \# of trial } & \multicolumn{2}{c}{ average \# of response* } \\
\cline { 2 - 5 } & number & $\begin{array}{c}\text { elapsed } \\
\text { time }\end{array}$ & number & $\%$ \\
\hline $10-\mathrm{min}$ & 73 & $730 \mathrm{~min}$ & 22 & $30.1 \%$ \\
\hline $30-\mathrm{min}$ & 75 & $2,250 \mathrm{~min}$ & 34.2 & $45.6 \%$ \\
\hline $60-\mathrm{min}$ & 39 & $2,340 \mathrm{~min}$ & 22.6 & $57.9 \%$ \\
\hline
\end{tabular}

* average \# of response at questionnaire at least 1 time

Table 4 shows that 30-min group's number of full need was more than those of other groups. 60-min group's extracting number of needs was more than those of other groups. It means that 60 -min group is the most effective.

Table 4. Efficiency

\begin{tabular}{c|c|c|c|c}
\hline & $\begin{array}{c}\text { \# of pre- } \\
\text { defined needs }\end{array}$ & $\begin{array}{c}\text { extracting } \\
\text { \# of needs }\end{array}$ & \# of full need* & $\begin{array}{c}\text { \# of trial for } \\
\text { full need }^{* *}\end{array}$ \\
\hline 10-min & 9 & 3.41 & 1 & 31 \\
\hline 30-min & 9 & 3.35 & 2 & 66.5 \\
\hline 60-min & 9 & 3.89 & 1 & 11 \\
\hline
\end{tabular}

* who are response at 9 pre-defined needs

${ }^{* *}$ trial of deriving the full-set needs

To determine the effectiveness and efficiency of the measurement method, we analyze the cross-check between questionnaire response and extracting number of needs. As a result, 10-min and 60-min group's average number of need for person was same, as shown in Table 5. It means that 60-min group is the most effective. But its number of response was small.

Table 5. Response Rate and Needs

\begin{tabular}{c|c|c|c}
\hline & \# of response & $\begin{array}{c}\text { extracting \# of } \\
\text { needs }\end{array}$ & $\begin{array}{c}\text { average \# of need } \\
\text { for person }\end{array}$ \\
\hline 10-min & 17 & 3.41 & 0.20 \\
\hline 30-min & 23 & 3.35 & 0.15 \\
\hline $60-\min$ & 19 & 3.89 & 0.20 \\
\hline
\end{tabular}

As a result there are some patterns of need change as shown in Figure 5. We expected the result, as following. Human need existed multiple based. Among them, high 
expectation degree need leads to the decision of products and service and this change has some special patterns. Also the changing pattern can be predicted.

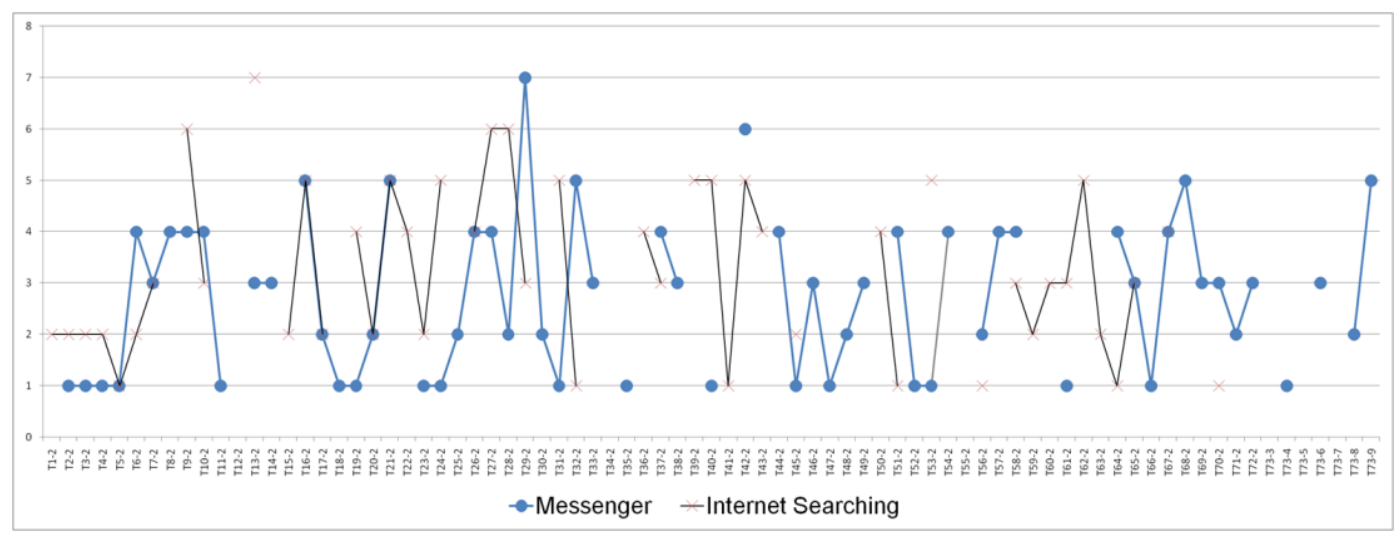

Figure 5. Some Patterns of Need Change

\section{Conclusion \& Implication}

Timeline-based multi-need analysis is a longitudinal approach by using the 'time' axis, in order to improve the limitation of existing cross-sectional approach to customer analysis. Business planner may have a chance to find out the new business opportunities by timeline-based multi-need analysis. Also marketer has a confidence to operate promotion programs to create and retain customers in the perspective of long-term.

Recently big data issues are arising and there are some requirements as developing a complex data mining tool/technique. The timeline-based multi-need analysis could give some evidence to develop more effective and efficient tools.

However, the reliability and validity of this measurement model did not secure a place; there are additional considerations to be made. (1) For the measurement of customers' needs, what is the most suitable time interval? We tried to verify the most useful timeinterval, small number of samples to ensure statistical significance was difficult. But we found a clue for finding out the optimal time interval based on response rate and the number of extracting new needs. Overall 30-minute group was optimal to ensure the effectiveness and efficiency of survey.

In addition question, (2) Changes in customers' needs are the most accurate analysis of any approach will be able to? We use smartphone application, Kakao talk. But the respondents were difficult to answer the repeated questions. So we will try to develop an application that is gathering the status automatically by checking the applications that are used.

This study analyzes the existing research on the customer focused on a specific target audience, while the user is not aware, but needs to have the opportunity for awakening, that needs to be designed for. Big data processing techniques are also improved in the reliability can be improved much more, as well as a logic-based algorithm can be used as a guide for experiment design.

Further research will be focused on the alternative research design that is predefined the need types by FGI and measure the expected level of each type of need of smartphone.

\section{References}

[1] H. Y. Joo, Y. W. Seo and M. J. Kim, "Market formation approach for the IT convergence business development - case application : serious game", Journal of Korea Institute of Information Technology, vol. 8, no. 9, (2010), pp. 161-173.

[2] P. Kotler and G. Armstrong, "Principles of Marketing", (1991). 
[3] J. Arndt, "How broad should the marketing concept be?", Journal of Marketing, vol. 42, no. 1, (1978), pp. 101-3.

[4] L. G. Schiffman and L. L. Kanuk, "Consumer Behavior", 7th edition, (2000).

[5] H. Y. Joo and M. J. Kim, "Concept of the need coexistence model for finding ICT convergence business opportunities", Future Information Technology, Application, and Service, LNEE, vol. 179, (2012), pp. 269-274.

[6] A. W. Ulwick, "What customers want", McGraw-Hill, New York, (2005).

[7] L. A. Bettencourt and A. W. Ulwick, "The customer-centered innovation map", Harvard Business Review, vol. 11, no. 1, (1994), pp. 3-14.

[8] D. Leonard and J. F. Rayport, "Spark innovation through empathic design", Harvard Business Review, vol. 75, (1997), pp. 102-115.

[9] K. Holt, H. Geschka and G. Peterlongo, "Need assessment: A Key to user-oriented product innovation", Wiley, (1984).

\section{Authors}

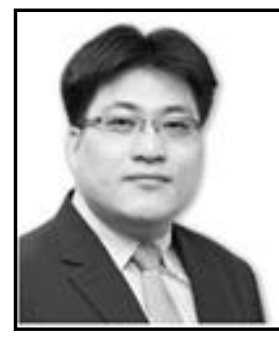

Joo Hi-Yeob first author, is a researcher in Korea Electronics Technology Institute, Republic of Korea. He has previously been on research professor in the Chung-Ang University(2009-2013), the deputy director at Korea SW Industry Promotion Agency(KIPA)(2007-2009) and junior consultant at Dongbu CNI(2005-2007), IT service corporation. He received M.S.(1999) and Ph.D.(2003) in Management Information Systems(MIS) and B.S.(1996) in Business Administration from the Chung-Ang University in Korea. His primary research interests include Convergence Business Modeling, Service Design, New Service/Product Development, Service Science and e-Business Strategy.

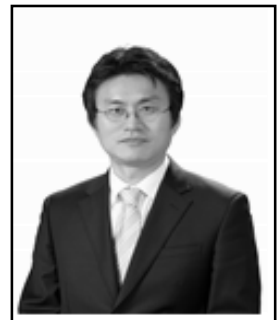

Park Jong-Oh, corresponding author, is an associate professor of marketing in the Department of Business Administration at the Soongeui Women's College, Republic of Korea. He holds a Bachelor's Degree in Business Administration, a Master's Degree and Ph.D. in Marketing obtained from the Chung-Ang University in Korea. His primary research interests include Marketing, Consumer Behavior, Semiotic Marketing, Integrated Brand Communication and Marketing Strategy.

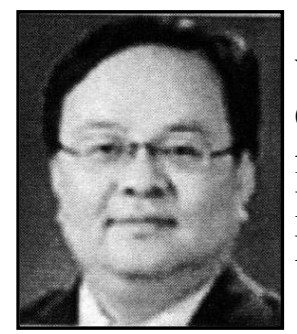

Sea-WoojhKimis is an assistant professor of Soong-Eui Women's College, Republic of Korea. He received B.S.(1990) in Computer Science and M.S.(1992) in Industrial Engineering from University of Michigan. He received $\mathrm{Ph}$. D from KAIST. His primary research interests include Big data analysis, Social Network Analysis, and Mobile Programming 